\title{
A EPISTEMOLOGIA \\ DIALÓGICA DA ANÁLISE \\ LINGUÍSTICA
}

\section{LA EPISTEMOLOGÍA DIALÓGICA DEL ANÁLISIS LINGÜÍSTICO}

\author{
DIALOGIC EPISTEMOLOGY IN LINGUISTIC ANALYSIS
}

\author{
Adriana Delmira Mendes Polato* \\ Universidade Estadual do Paraná \\ Renilson José Menegassi* \\ Universidade Estadual de Maringá
}

\begin{abstract}
RESUMO: O artigo discute a epistemologia teórica da prática pedagógica de Análise Linguística (AL) na Linguística Aplicada do Brasil. Trata-se de abordagem documental e dialógica à compreensão da arquitetônica individual e conjunta de três textos fundantes dos pressupostos norteadores da proposição, refratada e refletida em conceitos que compõem a AL, dispostos em: O texto na sala de aula (GERALDI, 2006 [1984]), Criatividade e gramática (FRANCHI, 1987) e Portos de passagem (GERALDI, 2013 [1991]). Os resultados demonstram que a AL nasce oscilando entre as perspectivas cognitivista e dialógica (GERALDI, 2006 [1984]) e pende a uma perspectiva mais dialógica (GERALDI, 2013 [1991]), por meio da reenunciação pictórica de vozes teóricas consoantes (FRANCHI,1987) e de vozes dos teóricos do Círculo de Bakhtin. Decorre uma configuração teórica epistemológica dialógica, assentada em um tripé sobreposto de apreensões de ordem cognitiva, ética e estética, cujos fundamentos pragmático-pedagógicos e sociais direcionam-se à compreensão/produção valorada do discurso e à transformação de relações sociais.
\end{abstract}

PALAVRAS-CHAVE: Análise Linguística. Epistemologia. Dialogismo.

RESUMEN: Este artículo discute la epistemología teórica de la práctica pedagógica del Análisis Lingüístico (AL) en la Lingüística Aplicada de Brasil. Se trata de un abordaje documental y dialógico para la comprensión de la arquitectónica individual y conjunta de tres textos fundacionales de los supuestos teóricos orientativos de la proposición, refractada y reflejada en conceptos que

Professora doutora do Colegiado de Letras e do Programa de Pós-graduação Interdisciplinar Sociedade e desenvolvimento da Universidade Estadual do Paraná - PPGSED/UNESPAR - Câmpus de Campo Mourão - PR. E-mail: ampolato@gmail.com.

Professor doutor do Departamento de Teorias Linguísticas e Literárias e do Programa de Pós-graduaça em Letras da Universidade Estadual de Maringá - PR - PLE/UEM.E-mail:renilson@wnet.com.br. 
componen el AL, expuestos en: O texto na sala de aula (GERALDI, 2006 [1984]), Criatividade e gramática (FRANCHI, 1987) e Portos de passagem (GERALDI, 2013 [1991]). Los resultados demuestran que el AL nace oscilando entre las perspectivas cognitivista y dialógica (GERALDI, 2006 [1984]) y pende a una perspectiva más dialógica (GERALDI, 2013 [1991]), por medio de la reenunciación pictórica de voces teóricas consonantes (FRANCHI,1987) y de voces de los teóricos del Círculo de Bakhtin. Resulta en una configuración teórica epistemológica dialógica, asentada en un trípode sobrepuesto de aprehensiones de orden cognitivo, ético y estético, cuyos fundamentos pragmático-pedagógicos y sociales se direccionan a la comprensión/producción valorada del discurso y a la transformación de relaciones sociales.

PALABRAS-CLAVE: Análisis Lingüístico. Epistemología. Dialogismo.

ABSTRACT: The present article discusses the theoretical epistemology of the pedagogical practice of Linguistic Analysis (LA) in Brazilian Applied Linguistics. It adopts a documentary and dialogic approach to understanding both the individual and combined architecture of three founding texts for the guiding assumptions of the thesis, which is deflected and reflected in concepts comprising LA in: O texto na sala de aula (The text in the classroom) (GERALDI, 1984), Criatidade e gramática (Grammar and creativity) (FRANCHI, 1987), and Portos de passagem (Ports of passage) (GERALDI, 1991). Results reveal that LA emerges torn between cognitive and dialogic standpoints (GERALDI, 1984), while more strongly leaning towards a dialogic approach (GERALDI, 1991) by virtue of a pictorial re-enunciation of concordant theoretical voices, such as Franchi's (1987) and The Bakhtin's Circle. Thus, a theoretical, epistemological, dialogic approach arises on the grounds of a tripod onto which assumptions of cognitive, ethical and esthetic nature are superimposed and to which pragmatic-pedagogical as well as social basis are directed not only towards comprehension and valuational production of discourse but also towards the transformation of social relations. KEYWORDS: Linguistic analysis. Epistemology. Dialogism.

\section{INTRODUÇÃO}

A revisitação epistemológica do objeto Análise Linguística (AL) no campo da Linguística Aplicada do Brasil (LA), a partir de O texto na sala de aula (GERALDI, 2006 [1984]), Criatividade e gramática (FRANCHI, 1987)e Portos de passagem (GERALDI, 2013 [1991]), é uma discussão dialógica, retrospectiva e prospectiva (BAKHTIN, 2003d), a esclarecer uma arquitetônica proposicional ainda basilar, cujos conceituais teóricos e metodológicos exarados em ancoragem dialógica ainda são constantemente reenunciados no campo científico, de forma convergente ou desviada à base fundante. Por isso, a relevância de ser mais bem compreendida e esmiuçada, de fazê-la emergir em forma de discurso linear para aprofundamento da proposição e da necessidade de caracterizar seus pilares.

A postura de revisitação assume a teoria dialógica do Círculo de Bakhtin como voz majoritária constitutiva da AL e como lugar de partida à interpretação da proposta. A análise dialógica do discurso epistemológico da AL está coadunada à natureza de análise documental que atribuímos ao corpus, tomado valorativamente deste ponto de vista, justamente por os textos integrantes constituírem marcos axiológicos no campo da LA do Brasil, até o momento tomados como fontes não reativas, ou seja, de informações replicadas ou ampliadas sem revisitação epistêmica, já há mais três décadas.

O surgimento da AL na LA do Brasil, como perspectiva de ensino gramatical e, sobretudo, como uma alternativa pedagógica de reflexão sobre a língua em uso, logo na primeira metade dos anos 80, integra o curso do movimento epistemológico de reconfiguração do ensino de língua materna no país, até então refratário, reduzido de abordagens gramaticais normativas e descritivas, as quais as contribuições gerais da Linguística e da Linguística Aplicada apontam as limitações e propõem expansões no dado contexto histórico, o que continua em vigência nos desenvolvimentos das pesquisas em AL na LA do Brasil.

Neste sentido, a explicitação da epistemologia dialógica refrata e reflete luz a compreender como, atualmente, a prática de Análise Linguística tem se constituído sob desenvolvimentos teóricos e analíticos heterogêneos, ora em ligação a práticas de leitura ou escuta, ora em ligação a práticas de produção textual oral ou escrita, em abordagens enunciativas e discursivas, majoritariamente sob perspectivas diversas de trabalho com os gêneros discursivos, conforme também recomendado nos documentos orientadores para o ensino de língua no país, como PCN (BRASIL, 1998), DCE-PR (PARANÁ, 2008) e BNCC (BRASIL, 2017). Traz luz refratária 
e reflexiva, da mesma forma, às discussões sobre a importância da AL como práxis necessária na formação inicial e continuada de professores, ou àquelas a envolver aspectos de práticas docentes, do uso de livros/materiais didáticos, ou de elaboração coautoral de materiais didáticos à aplicação em sala de aula. A abordagem realizada expõe limites e intersecções de ordem cognitiva e dialógica.

\section{A ARQUITETÔNICA DE O TEXTO NA SALA DE AULA}

A arquitetônica de O texto na sala de aula (2006 [1984]), organizada por Geraldi, reúne uma coletânea de doze artigos dos quais o próprio é autor de cinco. Todos dialogam em continuum coerente, de modo que a direção do todo valorativo da obra (BAKHTIN, 1988a) convoca a práticas de ensino e aprendizagem ancoradas em uma concepção de linguagem como forma de interação e transformação humana e social, para além de abordagens tradicionais. A proposição geral é estreitamente remetente a pressupostos do pensamento do Círculo de Bakhtin que sustentam a epistemologia de uma Análise Dialógica de Discurso (ADD) (BRAIT, 2008), como os exarados em Marxismo e filosofia da linguagem (BAKHTIN/VOLOCHINOV, [1924] 2006), quando se discute a interação verbal no centro das relações sociais (DAHLET, 2005), o conteúdo ideológico presente nas manifestações discursivas, como uma via a interpretação dos lugares instituídos que os sujeitos ocupam no contexto da vida sócio-historicamente organizada. Por adição e necessidade, se embate as correntes filosóficas subjetivo-individualistas e objetivo-abstratas do pensamento linguístico, que distanciam a abordagem da língua(gem) de uma interpretação sociológica.

As relações entre ideologia e linguagem, na ordem política e social, permeiam a arquitetônica, como se apresenta nos artigos que compõem o primeiro tópico do livro - Fundamentos. Logo no artigo de abertura, Ensinar Português (ALMEIDA, 1984), questionase o ensino de sintaxe a crianças pobres, que aprendem o sujeito da oração, mas não a serem sujeitos da própria vida e história. Posteriormente, os artigos de Chiappini e Osakabe discutem, em via mão dupla, o lugar de constituição do sujeito no ensino de língua e o lugar do fenômeno literário nas práticas de constituição do sujeito, discutindo sobre as abordagens normativas e descritivas da língua que precisam ser combatidas porque restringem a formação do sujeito aluno à ordem cognitiva, da repetição e, logo, da manutenção do estado das coisas. Está aqui manifestada, em O texto na sala de aula (2006 [1984]), já o cerne da base epistemológica dialógica direcionada aos objetivos de cunho social de um ensino de línguas capaz de formar sujeitos críticos para agir socialmente por meio da língua(gem), a fim de mover valores que regem as relações sociais. Essa base social envolve a compreensão dialógica do sujeito e da língua, os quais serão caracterizados em síntese.

Ainda no tópico Fundamentos, por um viés que adere pictoricamente vozes da Sociolinguística, apresentam-se dois artigos de Possenti: um que reflete sobre questões políticas acerca do ensino de gramática, outro que discute questões ligadas à compreensão ideológica da legitimidade das variações linguísticas não padrão, ao mesmo tempo em que reafirma o papel político e social da escola como agência que deve ensinar a variação padrão. Todos esses artigos acabam por reverberar posturas do Círculo de Bakhtin ao conceber os sujeitos, a língua e o papel da interação discursiva na relação com o que se manifesta em textos/enunciados.

Basta que se tome o ensaio Discurso no Romance (BAKHTIN, 1988b), por exemplo, onde se pode "encontrar ideias que hoje são mobilizadas pela Sociolinguística, pela Linguística Aplicada, pelas diferentes teorias e análises de discurso, as quais têm a ver com uma postura histórica, social, diante das linguagens, da/s língua/s e dos sujeitos" [...] evidenciando o constitutivo movimento entre unificação, centralização das ideologias verbais, orientação para a unidade e plurilinguismo real" (BRAIT; PISTORI, 2012, p 380, grifo das autoras), para que se perceba como as discussões em $O$ texto na sala de aula giram em torno de questões ideológicas inerentes ao uso da linguagem, que dizem "dos valores e das tensões que regem o mundo" (BRAIT; PISTORI, 2012, p. 382).

Para atender a essa prerrogativa, o intuito discursivo da coletânea passa pela reconfiguração das práticas de leitura, de produção textual escrita e de ensino de gramática, tendo-se a análise linguística como atividade nova, de cunho reflexivo, neste primeiro momento vinculada à reescrita do texto do aluno nas atividades linguísticas propostas à vivência em sala de aula.

Nesse ínterim, o leitor é preparado à novidade da Análise Linguística. Geraldi (2006 [1984]) problematiza: “[...] uma coisa é saber a língua, isto é, dominar habilidades de uso em situações de interação, entendendo e produzindo enunciados, percebendo diferenças 
entre uma forma de expressão e outra" (GERALDI, 2006, p. 46), outra é dominar a metalinguagem. A problematização remete à abordagem sociológica da língua, de forma subjacente às enunciações concretas (BAKHTIN/VOLOCHINOV, 2006c), de modo que o enunciado abarca relações sócio-historicamente possíveis entre sujeitos, as quais só a língua carregada de valores pode representar. Do método sociológico de estudo da língua, Geraldi só não considera o lugar e o papel das formas típicas de enunciado - os gêneros do discurso.

Na seção Unidades básicas do Ensino de Português, o autor defende que a metalinguagem e a normatividade cedam lugar à epilinguagem. Se ainda não considera os gêneros, Geraldi ensaia tratar o enunciado de forma similar ao que faz Bakhtin em "O problema do texto na linguística, na filologia e em outras ciências humanas" (BAKHTIN, 2003c), onde se delineia o estatuto do enunciado, a partir da consideração de três pontos-chave: a) a observação da situação sócio-histórica imediata e ampla de interação que representa, ou seja, as suas condições de produção; b) "a sua ideia (intenção)" (BAKHTIN, 2003c, p. 308); c) "a realização dessa intenção" (BAKHTIN, 2003c, p. 308). A abordagem mais completa que engloba considerações responsivas a esse tripé é efetivada por Geraldi (2013 [1991]), mais tarde, em Portos de Passagem. No entanto, em O texto de sala de aula, os fortes prenúncios de uma epistemologia dialógica para conceber a interação discursiva e o trabalho com o enunciado aparecem na arquitetônica da obra e parcialmente se manifestam no conceito teórico metodológico de AL apresentado.

Geraldi inicia uma conversa para afirmar a necessidade de se partir do texto produzido pelo aluno, com o objetivo de promover sua reescrita, de acordo com o aspecto eleito como tema de análise ou de melhoria. Metodologicamente, o autor fornece as linhas para a prática de Análise Linguística e afirma que seu princípio fundador é “[...] partir do erro para a autocorreção” (GERALDI, 2006 [1984], p. 74). Ao abordar de maneira direta e assertiva o conceito de "erro", deixa escapar a voz do tradicionalismo, ainda presente em seu discurso que se quer de ruptura. Já ao escolher a ideia de autocorreção, prenuncia o objetivo final de que saber operar sobre a língua compõe a capacidade e a habilidade do sujeito produtor para melhorar o próprio texto e, consequentemente, melhorar sua qualidade de resposta social nas situações configuradas de interação discursiva, o que deixa entrever a importância do desenvolvimento da autoria. No rodapé da página, a proposição conceitual teórico-metodológica de Análise Linguística é lançada:

O uso da expressão "prática de análise linguística" não se deve ao mero gosto por novas terminologias. A análise linguística inclui tanto o trabalho sobre questões tradicionais da gramática quanto questões amplas a propósito do texto, entre as quais vale a pena citar: a coesão e a coerência internas do texto; adequação do texto aos objetivos pretendidos; análise dos recursos expressivos utilizados (metáforas, metonímias, paráfrases, citações, discursos direto e indireto, etc.); organização e inclusão de informações; etc. Essencialmente, a prática de análise linguística não poderá limitar-se à higienização do texto do aluno em seus aspectos gramaticais e ortográficos, limitando-se a "correções". Trata-se de trabalhar com o aluno o seu texto para que ele atinja seus objetivos junto aos leitores a que se destina (GERALDI, 2006, p 74).

O primeiro ato é sustentar o valor epistemológico do termo. Posteriormente, Geraldi (2006 [1984]) não exclui o tratamento tradicional de questões gramaticais. Na sequência, anuncia que a prática de análise linguística envolve "questões amplas a propósito do texto", mas busca as vozes da Linguística de Texto de linha cognitivista para recomendar a abordagem da coesão e da coerência internas. A ruptura com os discursos tradicional e estruturalista é ventilada em seguida, quando postula que a AL deve visar à "adequação do texto aos objetivos pretendidos". Em fio tênue de oscilação entre o tradicional e o inovador, o conceito de AL começa a ser constituído, de modo retrospectivo e prospectivo (BAKHTIN, 2003d), em embate que se quer dialógico.

Geraldi defende a formação de um sujeito que domina a língua, a gramática e produz discurso a partir de reflexão social. O autor enfatiza que a abordagem de questões de gramática é respondente aos critérios de adequação do texto aos seus objetivos interacionais. No entanto, o modo como apresenta essas proposições em separado deixa entrever o reforço à tradição gramatical, conforme se observa: "A análise linguística inclui tanto o trabalho sobre questões tradicionais da gramática quanto questões amplas a propósito do texto” (GERALDI, 2006, p. 74). Sabemos que essa não é a vontade discursiva do autor, por duas razões: a) na segunda nota de rodapé, na mesma página, ele complementa: “[...] chamo atenção aqui para os aspectos sistemáticos da língua e não para a terminologia gramatical com que a denominamos. O objetivo não é o aluno dominar a terminologia gramatical (embora possa usála), mas compreender o fenômeno linguístico em estudo" (GERALDI, 2006 [1984], p. 74); b) a arquitetônica da coletânea é de combate à redução do ensino da língua ao descritivismo ou ao normativismo, a conclamar a abordagem de questões sociais no 
ensino de línguas por meio do trabalho com o enunciado.

A oscilação entre o tradicional e uma proposta mais dialógica é constitutiva do discurso conceitual da AL e se marca velada, por exemplo, na recomendação para o trabalho com figuras de linguagem, como a metáfora e a metonímia. A arquitenônica de $O$ Texto na sala de aula nos permite depreender que Geraldi está para além de um projeto retórico tradicional. Ele visa a um projeto discursivo a partir da base interlocutiva, pois, ao mencionar as figuras de linguagem, logo quando aborda a questão do trabalho com a escrita de textos, acaba por remeter à ideia de que os recursos expressivos da língua estão disponibilizados à expressão volitiva do sujeito (BAKHTIN, 2003b), que age social e conscientemente ao fazer escolhas assentadas no plano axiológico compartilhado (BAKHTIN, 1988a; VOLOCHINOV/BAKHTIN, 1926) com o interlocutor/ouvinte, já participante de seu diálogo interior. O reconhecimento de condutas sociais que regem o quem sou eu, o quem é você no cronotopo se concretiza na orientação complementar: "Trata-se de trabalhar com o aluno o seu texto para que ele atinja seus objetivos junto aos leitores a que se destina" (GERALDI, 2006, p 74). Neste sentido, a prática de análise linguística não se limita à higienização do texto do aluno, a correções gramaticais, apenas. A enunciação nova, singular, como propôs o Círculo de Bakhtin, passa a ser considerada. Assim, no que toca à abordagem das questões gramaticais, prenuncia-se, de certo modo, que deva se realizar no trabalho com o enunciado a partir da consideração da relação estilo-gramática (BAKHTIN, 2003b, 2013).

Do mesmo lugar, Geraldi se preocupa com a paráfrase, com o discurso direto e indireto, mas não ventila a possibilidade de reinterpretar as bases analíticas tradicionais desses objetos a partir de outras de ordem sociológica dirigidas à compreensão da composição dialogizada e valorada do discurso, como o faz Bakhtin/Volochinov (2006f, 2006g, 2006h), por exemplo, ao tratar das peculiaridades que envolvem a relação entre a sintaxe e o discurso citado.

O delineamento da Análise Linguística na obra permite compreender que a questão toda da oscilação está atravessada por três aspectos que apenas os desenvolvimentos mais atuais das pesquisas nos permitem visualizar: a) não há sugestão de reinterpretação para as bases cognitivas e tradicionais convocadas à análise dos objetos; b) a compreensão da base epistemológica dialógica se apresenta bem constituída para o próprio autor do ponto de vista social, mas não os desenvolvimentos complementares que poderiam trazer refinamento à proposta pedagógica pragmática para abordagens dos objetos, hoje possível; c) em termos da apreensão apreciativa do discurso, o contexto não permite interpretações fundamentalmente dialógicas pelo leitor.

Ademais, toda esta questão que envolve diálogos de bases dialógicas com bases cognitivistas no tratamento de aspectos linguísticos na ordem da Análise Linguística mostra-se não completamente resolvida pela Linguística Aplicada desde 1984 e só começa a se modificar no panorama das pesquisas em AL na presente década, como demonstra Polato (2017), para quem é necessário que se movam as bases analíticas, ou minimamente, em postura dialógica, que se possa revesti-las de interpretações sociovalorativas com ancoragem teórica e metodológica mais refinada, mais bem delineada, como se nota em Polato e Menegassi (2017).

Se o leitor atenta a compreender toda a arquitetônica da obra, verá que, ao discutir o uso da escrita e, especialmente, a avaliação da escrita no último capítulo do livro, Geraldi chama atenção para o fato de, na escola, não se produzirem textos “[...] em que um sujeito diz sua palavra” (GERALDI, 2006 [1984], p. 128). A luta política do Círculo de Bakhtin diz respeito à ideia de se ter palavra própria, o que envolve a abordagem axiológica, ou seja, a tomada de juízos de valor, da entoação social circunscrita a temas e interlocutores, por sua vez, (co)dependentes do extraverbal da enunciação, a envolver a história social mais ampla e imediata da enunciação (VOLOCHINOV/BAKHTIN, 1926; BAKHTIN, 1988a,b).

A epistemologia que conclama os usos sociais da linguagem como emancipatórios atravessa toda a arquitetônica das obras analisadas. No último capítulo, porém, mostra força veemente. Aqui, Geraldi ressalta que qualquer proposta metodológica de ensino e aprendizagem de língua articula uma concepção de mundo e de educação e de sujeito, sendo um ato político. Atos, conforme preconiza o Círculo de Bakhtin, são manifestações éticas de agir (BAKHTIN, 2010). Geraldi sustenta a defesa da formação da subjetividade do aluno que escreve na escola, porque acredita que retirá-la significa impossibilitá-lo de constituir-se como indivíduo próprio em práticas de linguagem. A articulação interacional proposta a ser vivida em sala de aula, em termos de mediação, sugere que o professor se desloque de seu lugar costumeiro frente ao aluno, tornando-se interlocutor dele, respeitandolhe a palavra e, sobretudo, sendo seu parceiro, concordando, acrescentando, questionando quando discutem sobre o texto. 
Por todas as questões arroladas, é possível mostrar que, neste primeiro momento, a AL nasce cognitiva e tradicional na direção da abordagem prática de objetos e dialógica na base epistemológica de cunho social prenunciada na arquitetônica da obra, ao trazer à tona a relação sujeito-ideologia-língua e discurso, (BAKHTIN/VOLOCHINOV, 2006a, b), cuja a reinterpretação no campo da LA clama por novas metodologias e posturas frente aos objetos de ensino convocados, isso sempre com vistas ao objetivo de promover a emancipação do sujeito, que, no plano teórico dialógico, é aquele que precisa se tornar autor para se refratar e refletir para vida social organizada via língua em uso, a partir de uma consciência social.

\section{A ARQUITETÔNICA DE “CRIATIVIDADE E GRAMÁTICA”}

Criatividade e gramática ${ }^{1}$ (FRANCHI, 1987) se concretiza em coerência enunciativa ao diálogo suscitado por Geraldi (2006 [1984]), da mesma forma que dispõe reflexões teóricas, conceituais e metodológicas reenunciadas em Portos de passagem (GERALDI, 2013 [1991]). Embora aqui não se utilize o termo Análise Linguística, as relações dialógicas, extralinguísticas ou extraverbais da enunciação estabelecem-se sob a ordem epistêmica do contexto. Por isso, "Criatividade e gramática" integra a epistemologia que constitui o discurso de nascimento da AL, assim como outros textos. No caso de Franchi (1987), nosso interesse é no modo como este traça uma proposta metodológica dialógica a possibilidades de novos fazeres no trabalho com a própria gramática. Do mesmo modo que Geraldi (2006 [1984]), ele rebate o ensino gramatical normativo e descritivo, representativo do "[...] trabalho de 'arquivamento' [da língua] e assujeitamento” (FRANCHI, 1987, p.6).

Do ponto de vista composicional e arquitetônico, a reflexão envolve as relações entre gramática e criatividade, em percurso de três momentos: a) rever a noção de criatividade, a partir da análise posicionada do discurso sobre o comportamento criativo e seus objetivos didáticos; b) recolocar críticas sobre a concepção de gramática vigente nas práticas escolares - a tradicional - sob o embate da relação criatividade em linguagem e ensino e aprendizagem; c) apresentar possibilidades de renovação do ensino gramatical sob indicações metodológicas certas. Essa base de indicações deve ser recuperada para o entendimento do que vêm a ser as atividades linguísticas, epilinguísticas e metalinguísticas delineadas pelo autor e mais tarde reelaboradas, reacentuadas por Geraldi (2013 [1991]). Para Franchi, o lugar de partida é a noção de criatividade, que aqui também é reinterpretada sob ótica dialógica da relação estilo-gramática.

Franchi defende que a criatividade na linguagem se manifesta idiossincraticamente na maneira como o sujeito do discurso se relaciona com o tema tratado, o que implica sobre as escolhas linguísticas, sobre as formas de estratificação do discurso próprio, de modo muito consoante ao que Bakhtin/Volochinov (2006d), Bakhtin (1988a, 1988b; 2003b) e Volochinov/Bakhtin (1926) tratam da importância do tema no enunciado, do estilo próprio, da habilidade autoral de escolha, apesar de não mencionar explicitamente essa relação teórica. $\mathrm{O}$ autor argui que a criatividade se manifesta nos processos por meio dos quais o falante estende esquemas relacionais, sintáticos ou semânticos, pela analogia ou pela metonímia para defender posicionamentos discursivos, questão também tratada por Geraldi, como vimos, e já explicitada em "O problema do conteúdo, do material e da forma na criação literária” por Bakhtin (1988a).

Para Franchi e Bakhtin, quando o falante ultrapassa os limites do codificado, manipulando o próprio material da linguagem, dandolhe significação própria, ele é autor, age socialmente por meio da linguagem. Bakhtin (1988a), por exemplo, defende o estilo próprio como condição a serviço da manifestação do posicionamento axiológico do autor-criador (FARACO, 2007), atividade que envolve o "sentimento [...] seleção do significado, pelo sentimento singular da iniciativa do sujeito-criador" (BAKHTIN, 1988a, p. 65, grifos do autor), a englobar "sua autonomia cognitiva e ética” (BAKHTIN, 1988a, p. 66). Para Franchi, essas são habilidades que envolvem operações com e sobre a linguagem e implicam "diferentes maneiras de conduzir o discurso", pois "a atividade do falante não é neutra" (FRANCHI, 1987, p. 18). Desse modo, o papel do autor, em seu ato social responsível, em termos das práticas de linguagem, envolve a relação estilo-gramática (BAKHTIN, 1988b, 2003b, 2013, 2010), conclamada por Franchi (1987): “[...] a gramática é um sistema aberto a uma multiplicidade de escolhas que permite não somente ajustar as expressões aos propósitos e intenções

${ }^{1}$ Referimo-nos ao artigo Criatividade e gramática, publicado em Trabalhos em Linguística Aplicada (1987), porque o próprio autor o avalia como mais bem elaborado e completo. 
significativas do locutor, mas ainda marcar cada texto, com a marca de um estilo, não menos expressivo por ser estilo" (FRANCHI, 1987, p. 43).

O plano metodológico para que a relação estilo-gramática seja abordada é dado por Franchi, sob a ótica do que chama trabalho criativo. Assim, o autor recomenda

[...] levar os alunos a operar sobre a linguagem, rever e transformar seus textos, perceber nesse trabalho a riqueza das formas linguísticas disponíveis para suas mais diversas opções. Sobretudo quando, no texto escrito, ele necessita tomar muitas vezes conscientes procedimentos expressivos de que se serve. Com isso, parece-[lhe], reintroduz-se na gramática seu aspecto criativo (FRANCHI, 1987, p. 21).

Franchi defende esta reflexão sobre a linguagem, no sentido de criação, projeto que associa à necessidade de renovação das práticas discursivas de produção e compreensão de textos na escola. Ele vislumbra uma renovação retórica, "[...] dando-lhe uma dimensão política e social mais moderna" (FRANCHI, 1987, p. 28), o que se aproxima dos estudos do Círculo de Bakhtin. Se retomarmos os desenvolvimentos dos estudos retóricos, desde a Retórica, de Aristóteles, aos estudos estilísticos que os substituíram no século XIX, observamos que Franchi deixa entrever o veio da relação estilo-gramática tratada pelo Círculo de Bakhtin. Tal raciocínio se aplica mediante a compreensão de que o papel de crítica e redefinição dos estudos estilísticos clássicos é bem feito pelo Círculo de Bakhtin (BAKHTIN, 1998a, 2003b, 2013), quando une uma nova visão sobre o estilo, que envolve o individual e o social. O Círculo leva a estilística clássica à berlinda, como explica Brait (2008), para prospectar uma abordagem sociossubjetiva, sociovolitiva, pluridiscursiva do estilo, à qual o ato de operar com e sobre língua está ligado ao trabalho do autor com o material/língua, já com consciência de seu valor social, do que parte para um arranjo próprio ao posicionamento axiológico peculiar manifestado em reforço ou refutação a outros. Portanto, como ser social, ele encorpa discursos da vida corrente.

Na terceira parte do artigo, Franchi dá indicações para a renovação dos estudos gramaticais. Relembra as práticas de seu antigo professor de Ensino Fundamental, que se propunha a "[...] estudar a variedade de recursos sintáticos expressivos, colocados à disposição do falante ou do escritor para a produção de sentidos" (FRANCHI, 1987, p. 35). A postura reverbera práticas que não destoam das mediadas pelo Bakhtin-professor, ao instigar alunos do $9^{\circ}$ ano de russo a refletirem sobre os efeitos axiológicos da presença ou ausência de conectivos em períodos compostos por subordinação, como se expõe no ensaio Questões de estilística no ensino de língua (2013). Os dois exemplos ilustram o prenúncio do que viriam a ser, na prática, as atividades epilinguísticas.

A abordagem de Franchi para o ensino de gramática é de linha dialógica, porque subjaz ao desenvolvimento do estilo, visto estar interessada em "[...] por que e como (para quem e quando) as expressões das línguas naturais significam tudo aquilo que significam" (FRANCHI, 1987, p. 35). Ao discorrer sobre o trabalho com o léxico, por exemplo, Franchi dispensa abordagens morfológicas tradicionais e sugere que, no processo de recomposição do texto, que podemos atualmente compreender como processos de revisão e reescrita (RUIZ, 2010; GASPAROTTO; MENEGASSI, 2013), as palavras possam ser aplicadas em direcionamento interlocutivo e temático, de modo que a atenção seja voltada a seu valor social, inclusive na construção sintática. A postura remete às abordagens sociológicas sugeridas por Bakhtin/Volochinov (2006 a, 2006d, e) para a palavra e para a sintaxe, do ponto de vista de uma composição valorada e dialogizada do discurso na enunciação concreta. O entrelaçamento ao dialogismo é evidente, mas não explícito.

Franchi delineia que as atividades linguísticas, epilinguísticas e metalinguísticas são a chave ao processo de ensino e aprendizagem da língua sob uma abordagem renovada da gramática. As primeiras dizem respeito às vivências sociais propostas a partir do trabalho de compreensão ou produção de textos. Elas devem ser praticadas com vigor nas primeiras séries da vida escolar, em "[...] exercício pleno, circunstanciado, intencionado e com intenções significativas da própria linguagem" (FRANCHI, 1987, p 39), a pressupor o diálogo, a conversa, a permuta, a contradição, o apoio recíproco, a constituição dos alunos como interlocutores reais do professor e dos alunos entre si. Já as atividades epilinguísticas devem ser intensas, provocadas e estimuladas pelo professor, para que aluno opere com e sobre a própria linguagem, ao comparar expressões, transformá-las, de modo a "[...] experimentar novos modos de construção, para investir as formas linguísticas de novas significações” (FRANCHI, 1987, p. 41), sob as bases de uma interpretação social. O trabalho linguístico e epilinguístico nos primeiros anos de escolaridade abriria as portas para uma sistematização 
gramatical e, somente a partir dela, mais tarde, o aluno poderia vir a falar sobre a língua, ou descrevê-la a partir de um quadro nocional intuitivo ou teórico, o que o autor nomeia como atividade metalinguística, a ser praticada apenas a partir das últimas séries do Ensino Fundamental.

Está delineada em Franchi (1987) a arquitetônica de cunho pragmático do trabalho reflexivo com a gramática. As práticas linguísticas, epilinguísticas e metalinguísticas arroladas pelo autor voltam-se ao desenvolvimento da autoria, do discurso próprio dos alunos e requerem a formação de um sujeito ético, que opera com e sobre a língua e não apenas repetidor cognitivo.

\section{A ARQUITETÔNICA DE PORTOS DE PASSAGEM}

Portos de passagem apresenta três capítulos e as discussões empreendidas em todos eles interessam ao objeto Análise Linguística, sendo mais veementes no primeiro e no último. Em Linguagem e trabalho linguístico, Geraldi põe em relevo a relação entre linguagem e desenvolvimento humano e discorre sobre um ensino de língua responsível a essa visão. A referência declarada a pressupostos do Círculo de Bakhtin reafirma a interação discursiva como lugar de revaloração da língua e de constituição dos sujeitos, de maneira consoante ao que discute Bakhtin/Volochinov (2006 a, b, c, d) em Marxismo e filosofia da Linguagem.

Para o autor, a negociação de sentido das expressões é altamente ligada à compreensão do interlocutor e a produção linguística dependente de “[...] operações de construção de sentidos destas expressões no próprio momento da interlocução" (GERALDI, 2013 [1991], p. 9). A importância do interlocutor/ouvinte como participante fundamental da fala do locutor é explicitada por Geraldi do mesmo modo como a enfatizam Bakhtin (1926, 1988a; 2003b), Bakhtin/Volochinov (2006c), Volochinov/Bakhtin (1926). Assim, Geraldi destaca o fenômeno interlocutivo por defender que o atendimento ao projeto interacional exige do locutor a consciência de operar com e sobre a língua(gem) para estreitar o projeto de compreensão lançado ao interlocutor em proposta de compartilhamento ideológico na enunciação concreta, o que traz influências a sua linguagem, a seu estilo. Geraldi (2013 [1991]), ainda, enfatiza que os recursos expressivos têm a sua garantia semântica assentada na situação extraverbal, extralinguística e no interlocutor, de modo a completar-se apenas no processo de compreensão. Por isso, referencia abertamente o método sociológico para estudo da língua proposto por Bakhtin/Volochinov (2006c) e reafirma que as condições em que os discursos são produzidos são imprescindíveis a sua compreensão. A coerência enunciativa da obra do Círculo permite-nos encontrar tal sintetize, em "O problema do conteúdo, do material e da forma na criação literária” (BAKHTIN,1988a): "[...] é sobre o fundo aperceptivo da compreensão, que não é linguístico, mas, sim, expressivo-objetal, que está orientada qualquer enunciação. Ocorre um novo encontro da enunciação com o discurso alheio, resultando uma nova influência específica em seu estilo” (BAKHTIN,1988b, p. 90).

Assim, expressa Geraldi que o trabalho linguístico é processual e interrupto, visto sempre produzir uma sistematização aberta, em que cada palavra ou expressão tanto está para a tendência à diferenciação valorativa que lhe confere a situação imediata de interação, quanto está para repetibilidade inerente à historicidade que permeia a produção discursiva (BAKHTIN/VOLOCHINOV, 2006a). Nesta visão, o modo idiossincrático como cada sujeito do discurso opera com e sobre a língua, sempre a partir do plano social, é de grande relevância e força social, como se confirma em Bakhtin (1988b, 2003b, 2013). A questão é filosoficamente profunda, porque Geraldi abraça a defesa do Círculo de Bakhtin de que é possível mover as relações sociais a partir do discurso, que não se constitui sem vontade, sem o uso consciente e deliberado da língua a este serviço, a partir de operações determinativas da semanticidade dos recursos expressivos utilizados, sem que o "eu" possa existir, sempre, diante e com "outro" cronotopicamente. Por isso, ao tratar da formação social da consciência do sujeito, Geraldi (2013 [1991]) declara: “[...] a consciência dos sujeitos forma-se neste universo de discurso e é deles que cada um extrai, em função das interlocuções de que vai participando, um amplo sistema de referências no qual, interpretando os recursos expressivos, constrói sua compreensão de mundo” (GERALDI, 2013 [1991], p. 33).

A partir dessa compreensão, Geraldi trata as operações linguísticas como ações/atos que os sujeitos fazem com e sobre a linguagem. Para que aprenda a fazer isso, o processo de ensino e aprendizagem da língua(gem), então, é ato de reflexão, na medida em que as ações linguísticas praticadas pelo sujeito nas interações propostas em sala de aula exigem compreender a fala do outro e fazer-se compreender pelos outros, em forma de diálogo, a partir do trabalho com os enunciados lidos/produzidos para abordagem de temas, o que mais uma vez se confirma nas discussões empreendidas por Bakhtin (2003c) em "O problema do texto na linguística, 
na filologia e em outras ciências humanas", onde se explicita que, na compreensão, obrigatoriamente, há duas consciências, dois sujeitos em diálogo. E o diálogo é social porque os sujeitos e os temas também o são.

Para Geraldi, toda ação linguística já está atrelada à reflexão sobre a linguagem a desencadear uma compreensão ativa em forma de contrapalavra de conflito ou de acordo sobre um tema, de modo que a compreensão responsiva ativa é dinâmica, por ter a propriedade de amadurecer na resposta, como apregoa Bakhtin (1988a).

Ao diferenciar ações que se fazem com a linguagem e ações que se fazem sobre a linguagem, Geraldi afirma que ambas constituemse como um trabalho. As primeiras clarificam o tipo de ato que se está praticando e as outras visam à produção de sentidos, tendo como campo privilegiado os recursos expressivos "para os quais a atenção do outro é chamada” (GERALDI, 2013 [1991], p. 42). Numa acepção prenunciada pelo Círculo de Bakhtin (1988a, 2003b), quando se é autor, significa que se interpreta condutas sociais envolvidas na interação e se é capaz de compreender o lugar e a posição do eu em relação ao outro. Esta compreensão autoral se manifesta concretamente nas escolhas linguísticas, gramaticais que o sujeito do discurso faz. Em visão similar, para Geraldi (2013 [1991]), as ações sobre a linguagem são responsáveis por deslocamentos de referências, construção de novos sentidos para os mesmos recursos gramaticais, visto incidirem sobre novas formas de representação no mundo. Esta sistematização aberta da língua, via ações de linguagem, interfere na construção de raciocínios lógico-linguísticos e está, em nível pedagógico, ligada à importância social das atividades linguísticas, epilinguísticas e metalinguísticas, assim como também propôs Franchi (1987). Geraldi (2013 [1991]), no entanto, emplaca seu diferencial em relação a Franchi (1987) ao afirmar que essas atividades integram práticas pedagógicas planejadas e mediadas de Análise Linguística, de modo que o conjunto dessas reflexões passa a mover a estrutura dos processos cognitivos, regular e mediar a atividade psíquica humana pela orientação dialógica. Quanto mais se reflete mais se instiga à compreensão e à resposta.

No segundo capítulo do livro, Identidade e especificidades do ensino de língua, Geraldi chama atenção para o fato de ser na área do ensino de gramática que se percebe mais claramente o processo de fetichização do que a ciência proclama, porque a distância entre o que pregam os pesquisadores e o que pensam os professores sobre a estrutura da língua é cada vez maior. Dessa falta de entendimento, mal resolvida, decorre que não se chega a um consenso sobre como ensinar gramática.

No capítulo três, intitulado No espaço do trabalho discursivo, alternativas, o autor defende a "[...] inserção das atividades linguísticas de sujeitos historicamente situados e datados como lugar da ação e como objeto da ação do ensino de língua materna” (GERALDI, 2013 [1991], p.135). Desse modo, delineia a produção de textos orais e escritos como ponto de partida e chegada de todo o processo e ensino e aprendizagem da língua e como ato político para dar voz às classes desprivilegiadas, sobretudo porque é no objeto de estudo - o texto, para Bakhtin (2003c, p. 319), "[...] dado (realidade) primário e ponto de partida para qualquer disciplina nas ciências humanas", que está ou se imprime o compromisso socioindividual com a palavra nova a ser devolvida ao social. Neste sentido, qualquer aspecto da "[...] expressão-enunciação [...] será determinado pelas condições reais da enunciação em questão, isto é, antes de tudo pela situação social mais imediata” (BAKHTIN/VOLOCHINOV, 2006c, p. 114, grifos do autor) de interação, que Geraldi abarca do ponto de vista do projeto interlocutivo. Por isso, o embate à redação, prática ligada ao domínio da repetição, à ordem cognitiva. Ao contrário disso, o processo de produção textual se liga ao posicionamento intersubjetivo de quem fala sob determinadas condições de produção. Nas palavras do autor, no processo de ensino e aprendizagem, ao ter o que dizer, ao ter razão para dizer, ao ter a quem dizer, o locutor se constitui sujeito que diz para quem diz - um jogador em jogo, em perspectiva dialógica mediada pelo professor.

A mesma perspectiva dialógica sugerida para o trabalho com a produção textual escrita é dada para o trabalho com a leitura, que para o autor já é integrante do processo de escrita. Somente depois dessa discussão, o autor passa a tratar especificamente da AL, quando é categórico ao afirmar: "[...] criadas as condições para as atividades interativas efetivas em sala de aula, quer pela produção de textos, quer pela leitura de textos, é no interior destas e a partir destas que a análise linguística se dá” (GERALDI, 2013 [1991], p. 189). O conceito de AL aqui sofre uma importante ampliação em relação ao postulado em O texto na sala de aula (2006 [1984]). A prática também passa a integrar o processo de leitura. $\mathrm{O}$ aluno-leitor assume o papel ativo de coprodutor de sentidos como na escrita. Ele interpreta as escolhas feitas pelo outro na forma de estratégias de dizer em dada situação, da mesma forma que as aplicaria se estivesse escrevendo. Mais que isso, ele apreende o discurso e suas formas linguísticas de organização na direção temática e 
também se posiciona diante disso. A contrapalavra está na direção dupla da leitura e da escrita para Geraldi. No último caso, a responsividade ativa (BAKHTIN, 2003b), a atividade de linguagem é mostrada e, no primeiro, nem sempre, o que não significa que não terá efeito social. Por isso, o autor defende que as práticas de escrita envolvem as de leitura, irremediavelmente.

A Análise Linguística está, do mesmo modo, para leitura/escuta, para a produção escrita/oral, em primeiro plano, como reflexão epilinguística que incide sobre a análise das estratégias de dizer intersubjetivamente construídas em dado projeto de interlocução. As atividades epilinguísticas, portanto, representam “[...] toda a reflexão sobre as diferentes formas de dizer a que aludimos [...] (especialmente no tópico 'o texto e as estratégias do dizer')" (GERALDI, 2013 [1991], p. 190). Do mesmo modo, as atividades metalinguísticas são consideradas pelo autor “[...] como uma reflexão analítica sobre os recursos expressivos, que levam à construção de noções com as quais se torna possível categorizar tais recursos" (GERALDI, 2013 [1991], p. 190-191). Percebemos que a visão de Geraldi sobre as atividades metalinguísticas incorpora um esforço para redirecionamento da interpretação de todas as questões linguísticas, incluindo as gramaticais, assim como propôs Franchi (1987), porque ele as toma como uma reflexão analítica e também as admite abertas. Nessa visão, as atividades metalinguísticas permitem falar sobre a linguagem, sobre seu funcionamento, sobre as configurações textuais “[...] e, no interior destas, o léxico, as estruturas morfossintáticas e entonacionais” (GERALDI, 2013 [1991], p. 191).

Na mesma linha de Franchi (1987), no plano metodológico, Geraldi defende que as atividades epilinguísticas antecedam as metalinguísticas em trabalho com o texto/enunciado. O autor, ainda, retoma o já postulado em O texto em sala de aula sobre análise linguística, para acrescentar a ideia principal de que a construção do texto envolve operações discursivas, relacionadas tanto à organização do próprio texto quanto à sustentação do discurso. Nesse caso, a língua com sua gramática é vista como sistematização aberta. As operações discursivas, então, são atividades de formulação textual que podem resultar de inúmeras atividades menores e quanto maior for o compromisso do locutor em "fechar" a proposta de compreensão ao interlocutor, maiores serão as operações discursivas que realizará. Esse processo é regido por ações com e sobre a linguagem. Se o produtor do texto não tem essa consciência deliberada, ele não pode se constituir autor de textos. Para Bakhtin (1988a), "[...] a atividade formativa do autor-criador e do contemplador domina todos os aspectos da palavra" (BAKHTIN, 1988a, p. 62). A palavra é cognitiva porque no enunciado cognitivo “[...] procura encontrar um lugar necessário na unidade objetal objetiva do conhecimento" (BAKHTIN, $1988 \mathrm{a}$, p. 62 - 63), mas, ao mesmo tempo "[...] o ato da palavra relaciona-se com a unidade do acontecimento ético e nela se define como necessário e imperativo” (BAKHTIN, 1988a, p. 63). Por isso é possível afirmar que Geraldi coteja o trabalho cognitivo e ético do sujeito autor de linguagem em situação de ensino e aprendizagem.

É desse modo que a Análise Linguística prenunciada em Portos de Passagem (2013 [1991]), relacionada tanto à leitura quanto à produção textual, parte do princípio de que saberes prévios cognitivos para domínio de expressões asseguram, em parte, a possibilidade de dirigir-se ao outro, mas são as “[...] operações de construção de sentidos destas expressões no próprio momento da interlocução" (GERALDI, 2013 [1991], p. 9) o que assegura a coprodução de sentidos na intercompreensão. Para Geraldi, é na dinâmica entre a repetibilidade e o novo que ocorre o trabalho linguístico e isso se dá quando "[...] trabalhamos na construção de sentidos 'aqui e agora' e para isso temos como 'material' [...] a língua que resultou de trabalhos anteriores" (GERALDI, 2013 [1991], p. 9), o que remete, mais uma vez, à ideia de língua viva, cumulativamente ideológica e em constante transformação, conforme preconiza Bakhtin/Volochinov (2006a).

\section{A EPISTEMOLOGIA DIALÓGICA DA ANÁLISE LINGUÍSTICA}

Nas arquitetônicas individuais e conjuntas das três obras analisadas, apresentam-se as relações entre as indicações teóricoconceituais e metodológicas exaradas na direção da AL, sob as bases dialógicas de sua sustentação, o que nos permite estabelecer uma síntese epistemológica que abarca duas dimensões: uma social e outra que diz das práticas de linguagem. Essas dimensões são indissolúveis, sobrepostas, para formar um conjunto de natureza dialógica. A primeira se amarra à segunda por meio de indicações metodológicas e é formada pelo tripé sujeito - língua - texto. O segundo tripé está reunido em torno do que isso representa em termos de práticas de linguagem vivenciadas em situação de ensino e aprendizagem, que envolvem operações que o sujeito faz com 
e sobre a língua em uso, que desfecham nas indicações de Geraldi (2006 [1984], 2013 [1991]) e Franchi (1987) para as atividades linguísticas, epilinguísticas e metalinguísticas.

\subsection{O SUJEITO}

O sujeito é um dos aspectos-chave para Geraldi (2006 [1984], 2013 [1991]) e Franchi (1987), como do mesmo modo o é para o Círculo de Bakhtin. É o sujeito sócio-histórico e ideológico que vai à escola para aprender a se tornar autor de linguagem e, por consequência, autor da própria vida. A atividade mental e a expressão desse sujeito está para a direção das forças sociais. Para tanto, ele deve se situar cronotopicamente, compreender de maneira ampla e imediata a configuração da situação sócio-histórica, cultural e ideológica de interação discursiva que o envolve e o constitui. Dotado dessa consciência social, deve ser capaz de compreendê-la e representá-la por meio da linguagem, de um ponto de vista, de uma determinada posição axiológica, que o permita ser, existir e viver com justiça, liberdade, sem opressões coercitivas, principalmente as de ordem econômica, cultural e política. Esse sujeito terá um estilo próprio de linguagem e, por decorrência, um estilo próprio na vida. Não se trata de um sujeito pronto, acabado. Ele é socioconsciente porque é altero e porque se constitui continuamente nas práticas discursivas. Desse modo, é respondente, aberto para si, inconformado, datado, ou seja, entrelaçado entre passado, presente e futuro na relação tempo-espaço. Como autor, ele aprende a dominar aspectos cognitivos de trato com a linguagem e do mesmo modo os aspectos sociovalorativos que a permeiam, conforme se demonstra no confronto linear trazido à tona pela análise de vozes comparadas no corpus. A AL, por conseguinte, se apresenta como uma prática que visa a formar autores com estilo próprio, que se refratam socialmente do mesmo modo. Essa é uma proposta ousada, que foi confrontada no contexto de produção científica do Círculo de Bakhtin, da mesma maneira como se apresenta confrontada no cenário político atual. O homem formatado mantém as coisas no lugar, mantém a ordem do dia. Não é esse sujeito formatado que a escola deve devolver à sociedade depois de mais de década de escolaridade básica. Isso só não acontecerá se ele puder fazer AL, para aprender o valor da vida do discurso e de sua própria.

\subsection{A LÍNGUA}

Tanto para os linguistas brasileiros como para os teóricos do Círculo de Bakhtin, a língua é sócio-histórica e ideológica como os sujeitos são. A língua, também, é heterogênea, não abstrata, não pronta, não estagnada, inconclusa, insolúvel, como nenhum sujeito pode ser, pois os sujeitos se refratam a partir dela, dos atos a que ela serve. Para que ambos não permaneçam estagnados, língua e sujeito, é necessário um processo que permita ao sujeito reconhecer-se, representar-se, constitui-se no e a partir dos usos da língua(gem), por meio de consciência social oriunda do diálogo entre o que lhe é interno e o que lhe é externo. A língua é esta ponte flexível. Nenhum valor do homem e da sociedade se move senão a partir da língua em constante valoração e vice-versa.

\subsection{O ENUNCIADO}

De acordo com Geraldi (2006 [1984], 2013 [1991]) e com Bakhtin (2003c), o texto é o dado, ponto de partida e de chegada de todo o fazer que envolve as ciências humanas e da linguagem. O texto, materialmente, representa relações sócio-históricas e ideológicas possíveis entre sujeitos também ideológicos, as quais só a língua carregada de valores pode representar e também permear o agir. Se visto a partir deste ponto de vista, o texto passa a ter valor de enunciado, mas não perde sua natureza material, que pode ser esmiuçada em estudo. Sobre os gêneros, Geraldi (2006 [1984], 2013 [1991]) não os abarca, mas deixa entrever que importam, porque são construções sociais sociovaloradas. É no estudo do texto que está ou se imprime o novo, de modo que ele se torna social ao remeter a um projeto enunciativo. As condições reais da enunciação, que envolvem sobretudo a situação de interação representada, é abraçada por Geraldi do ponto de vista do projeto interlocutivo. A escola não pode se prestar a restringir o trabalho com o texto à ordem dos aparatos cognitivos. Isso também não pode ser feito com os gêneros do discurso.

\subsection{AS ATIVIDADES LINGUÍSTICAS}

Como vimos, para Geraldi e Franchi, na escola, o sujeito ingressa para aprender a ser autor quando lê, quando escreve ou oraliza, ou seja, quando compreende ou produz textos/enunciados. Assim, a escola deve promover, primordialmente, no trabalho com o 
texto/enunciado, a vivência natural de situações configuradas de interlocução, para que se ressalte o fio da eventividade da enunciação concreta, que contém os detalhes que a diferenciam de uma repetição cognitiva. Não estamos equiparando texto e enunciado, como já explicamos, mas apenas considerando o primeiro como representação material do segundo, do mesmo modo como indica Bakhtin (2003c). Por isso, Geraldi delineia um projeto de interação que envolve professor-texto-aluno, não nesta vertical ordenada, mas em diálogo cíclico, aleatório, em que a vozes de todos são consideradas como legítimas, possíveis em contrapalavras, desde que possam ser reconhecidos e considerados acerca do tema tratado. Estas são as atividades linguísticas preconizadas para serem vivenciadas nas práticas de Análise Linguística.

\subsection{AS ATIVIDADES EPILINGUÍSTICAS}

Para os linguistas e linguistas aplicados brasileiros e para os teóricos do Círculo de Bakhtin, na epilinguagem está a base de toda a reflexão social e cognitiva que envolve o uso da língua, que, por sua vez, está ligado ao ato de operar com e sobre ela. Por isso mesmo, as atividades epilinguísticas sempre devem anteceder às metalinguísticas. A reflexão de base social se efetiva a partir da compreensão de todas as configurações sócio-históricas e ideológicas imediatas e amplas de interação - o que tanto está para a historicidade que, cumulativamente, permite aludir a possíveis efeitos de sentidos instaurados em uma palavra, uma expressão, quanto está para os possíveis efeitos de sentidos específicos configurados a partir da situação imediata de interação no evento interlocutivo. Prenunciase, também, na epistemologia da AL, que sejam consideradas as relações dialógicas que o enunciado mantém com outros, o entrecruzar valorativo de vozes da composição do discurso, isto não de modo aberto como já propõem teórica e metodologicamente estudiosos da linguagem de linha dialógica na atualidade, como Brait e Pistori (2012), Acosta-Pereira (2013), Polato e Menegassi (2017), Sobral e Giacomelli (2018), mas, naquele contexto, a partir de que já se considera a historicidade inerente. Portanto, as atividades epilinguísticas estão assentadas no que se denomina na tradição da LA do Brasil de fio discursivo para o ensino, na compreensão de que condições de produção são configuradoras de efeitos de sentidos. As atividades epilinguísticas devem ser mediadas pelo professor com a finalidade de investir as formas linguísticas de novas significações. Em nível pragmático, a epilinguagem parte da materialidade e questiona: quem está falando, de onde está falando, para quem está falando, quando está falando, por que está falando, de que posição fala, que vozes mobiliza, como as mobiliza, que valores compartilha neste projeto de compreensão lançado ao interlocutor e, por fim, desfecha: como esta escolha linguística está representando todos esses aspectos. $\mathrm{O}$ que representa do ponto de vista cognitivo e o que representa do ponto de vista valorativo? O que interessa aqui ser visto de um ponto de vista que se precisa apreender? Assim, as atividades epilinguísticas, também, são as responsáveis por desencadear a necessidade de compreender aspectos cognitivos, por serem essenciais a compor a formação do sujeito autor socioconsciente, deliberado, portador de estilo próprio, que detém capacidades de linguagem assentadas em compreensões de ordem cognitiva e sociovalorativa e não só cognitiva. Prenuncia-se, na epistemologia da AL, que os domínios citados são inseparáveis, pois se efetivam a partir da relação estilo-gramática.

\subsection{AS ATIVIDADES METALINGUÍSTICAS}

As atividades metalinguísticas foram preconizadas como integrantes das práticas de AL por Geraldi (2006 [1984], 2013 [1991]) e Franchi (1987) devido a sua importância enquanto responsáveis pela descrição científica do fenômeno a ser compreendido, para depois ser aplicado ao uso da língua. Do mesmo modo, Bakhtin (2013) já as havia concebido e demonstrado como imprescindíveis à formação de capacidades e habilidades, com vistas à coprodução de sentidos, ou compartilhamento de efeitos valorativos, do que resulta o enriquecimento da linguagem dos alunos. Elas se ancoram nas atividades epilinguísticas e partem da relação estilogramática, esta última concebida como sociovalorada, por já ser condição à escolha/realização estilística socioconsciente. As atividades metalinguísticas servem para, a partir da análise epilinguística da escolha linguística feita, conceituá-la, com base em conhecimentos já delineados e com base no que se apresenta como novo ali naquela análise. Esse conhecimento não necessita partir, necessariamente, do aporte gramatical, mas pode se utilizar de qualquer um de ordem cognitiva, desde que sua intepretação e descrição incorporem a intepretação valorativa inerente às condições dialógicas de produção, seja de modo intuitivo ou teoricamente ancorado. Esta é a prática metalinguística preconizada na epistemologia da AL. 


\section{CONSIDERAÇÕES FINAIS}

A arquitetônica dos três documentos analisados, em especial Portos de passagem (GERALDI, 2013 [1991]), último na cronologia a já incorporar os discursos dados em $O$ Texto na sala de aula e Criatividade e gramática, responde à mesma direção epistemológica social e pragmática conclamada pelos teóricos do Círculo, de modo a prospectar um delineamento dialógico à prática pedagógica de uma Análise Linguística. Franchi (1987) e Geraldi (2006 [1984], 2013 [1991]) elegem as atividades circunstanciadas de interação, ou evento de interlocução demarcada como locus avaliativo de intercompreensão subjetiva basilar para os usos da língua. Nesse ínterim, as atividades epilinguísticas unem os planos da cognição, da ética e da estética na compreensão/produção do discurso (BAKHTIN, 1988a, c, 2003a, b, c, 2010, 2013).

O plano da cognição é condição fundamental às respostas ativas mediadas por signos que o sujeito devolve ao plano social, enquanto o plano da ética conclama que possa oferecer essa resposta com palavras próprias, de modo responsável e verdadeiro (BAKHTIN, 1988a, 2003c, 2010, 2013). A vida e a produção discursiva exigem a relação de alteridade do sujeito com outro, cuja exotopia inerente permite, em situação de ensino e aprendizagem, ao sujeito-aluno, confrontar-se com os "eus" representados nos textos/enunciados que lê/produz, além de atentar ao acabamento estético respondente a uma proposta de tratamento temático compartilhado, que envolve amplos aspectos, como a interpretação de condutas sociais e valores ali convocados, o domínio da língua, da gramática e de outros saberes linguísticos e textuais, todos refratados e refletidos, em grande medida, a partir de estilo singular sociovalorado de linguagem, conforme propõe Franchi (1987). Isso porque, entre os processos éticos - fundados no dever de resposta responsável e estéticos - fundados na singularidade -, demanda-se o processo da cognição que rege a resposta, que construída a partir dessa compreensão dimensional imbricada nunca está para a reprodução ou reprodução automática do discurso, ou seja, para a réplica de reforço inconsciente de posições manifestadas em nível de forma e conteúdo - cópia.

Nestes termos, a AL epistemologicamente dialógica não se restringe a qualquer abordagem cognitiva da língua ou do texto/enunciado. Ela nasce dialógica, pelo contrário, é a prática que tensiona todas as dimensões da ação humana com e sobre a língua(gem) para compreensão/produção valorada do discurso. Quanto mais ampla, rápida e conscientemente o sujeito compartilhar e apreender valorações que permeiam a produção discursiva e souber utilizá-las para se posicionar no discurso e na vida, mais se refrata vivo, ativo e altero nas interações discursivas. Esses pontos asseguram os processos de revaloração da língua e dos discursos, o que, automaticamente, promove transformações individuais e sociais em certa direção.

\section{REFERÊNCIAS}

ACOSTA-PEREIRA, R. A reenunciação e as visadas dialógico-valorativas no gênero jornalístico notícia: projeções e discursividade. Revista Eletrônica de divulgação Científica em Língua Portuguesa. Linguística e Literatura Letra Magna, ano 09, n. 16, p. , 2013. Disponível em: http://www.letramagna.com/art_16_12.pdf. Acesso em: 10 set. 2013.

ALMEIDA, M. J. Ensinar português. In: GERALDI, J. W. (org). O texto na sala de aula. 4. ed. São Paulo: Ática, 2006 [1984]. p. 9-15.

BAKHTIN, M. O problema do conteúdo, do material e da forma na criação literária. In: BAKHTIN, M. Questões de literatura e de estética: a teoria do romance. Tradução Aurora Fornoni Bernardini et al. São Paulo: Ed. da UNESP, 1988a. p. 13-70.

BAKHTIN, M. O discurso no romance. In: BAKHTIN, M. Questões de literatura e de estética: a teoria do romance. Tradução Aurora Fornoni Bernardini et al. São Paulo: Ed. da UNESP, 1988b. p. 71-210.

BAKHTIN, M. O autor e a personagem. In: BAKHTIN, M. Estética da criação verbal. Tradução P. Bezerra. São Paulo: Martins Fontes, 2003a. p. 13-70. 
BAKHTIN, M. Os gêneros do discurso. In: BAKHTIN, M. Estética da criação verbal. Tradução P. Bezerra. São Paulo: Martins Fontes, 2003b. p. 261-306.

BAKHTIN, M. O problema do texto na linguística, na filologia e em outras ciências humanas. In: BAKHTIN, M. Estética da criação verbal. Tradução P. Bezerra. São Paulo: Martins Fontes, 2003c. p. 307-336.

BAKHTIN, M. Metodologias das ciências humanas. In: BAKHTIN, M. Estética da criação verbal. Tradução P. Bezerra. São Paulo: Martins Fontes, 2003d. p. 393-410.

BAKHTIN, M. Questões de estilistica no ensino de língua. Tradução Sheila Grillo e Ekaterina V. Américo. São Paulo: Editora 34, 2013.

BAKHTIN, M./ VOLOCHINOV, V. Marxismo e filosofia da linguagem. Tradução de Michel Lahud e Yara F. Vieira. 12. ed. São Paulo: Hucitec, 2006.

BAKHTIN, M./ VOLOCHINOV, V. Estudo das ideologias e filosofia da linguagem. In: BAKHTIN, M./VOLOCHINOV, V. Marxismo e filosofia da linguagem. Tradução de Michel Lahud e Yara F. Vieira. 12. ed. São Paulo: Hucitec, 2006a. p. 31-38.

BAKHTIN, M./ VOLOCHINOV, V. Relação entre as infraestruturas e as superestruturas. In:BAKHTIN, M/VOLOCHINOV, V. Marxismo e filosofia da linguagem. Tradução Michel Lahud e Yara F. Vieira. 12. ed. São Paulo: Hucitec., 2006b. p. 39-47.

BAKHTIN, M./ VOLOCHINOV, V. A interação verbal. In: BAKHTIN, M/VOLOCHINOV, V. Marxismo e filosofia da linguagem. Tradução Michel Lahud e Yara F. Vieira. 12. ed. São Paulo: Hucitec, 2006c. p. 110-127.

BAKHTIN, M./ VOLOCHINOV, V. Tema e significação na língua. In: BAKHTIN, M/VOLOCHINOV, V. Marxismo e filosofia da linguagem. Tradução Michel Lahud e Yara F. Vieira. 12. ed. São Paulo: Hucitec, 2006d. p. 128-138.

BAKHTIN, M./ VOLOCHINOV, V. Teoria da enunciação e problemas sintáticos. In: BAKHTIN, M/VOLOCHINOV, V. Marxismo e filosofia da linguagem. Tradução Michel Lahud e Yara F. Vieira. 12. ed. São Paulo: Hucitec, 2006e. p. $139-143$.

BAKHTIN, M./ VOLOCHINOV, V. Discurso de outrem. In: BAKHTIN, M/VOLOCHINOV, V. Marxismo e filosofia da linguagem. Tradução Michel Lahud e Yara F. Vieira. 12. ed. São Paulo: Hucitec, 2006f. p. 144-154. 
BAKHTIN, M./ VOLOCHINOV, V. Discurso indireto, discurso direto e suas variantes. In: BAKHTIN, M/VOLOCHINOV, V. Marxismo e filosofia da linguagem. Tradução Michel Lahud e Yara F. Vieira. 12. ed. São Paulo: Hucitec, 2006g. p. 155-173.

BAKHTIN, M./ VOLOCHINOV, V. Discurso indireto livre em francês, alemão e russo. In: BAKHTIN, M/VOLOCHINOV, V. Marxismo e filosofia da linguagem. Tradução Michel Lahud e Yara F. Vieira. 12. ed. São Paulo: Hucitec, 2006h. p. 174-204.

BRAIT, B. Análise e teoria do discurso. In: BRAIT, B. (org.). Bakhtin - outros conceitos-chave. São Paulo: Contexto, 2008. p. 9-32.

BRAIT, B.; PISTORI, M.H.C. A produtividade do conceito de gênero em Bakhtin e o Círculo. Alfa, São Paulo, v. 56, n. 2, p. 371-401, 2012. Disponível em: http://seer.fclar.unesp.br/alfa/article/view/5531. Acesso em: 3 jun. 2013.

BRASIL. Ministério da Educação. Secretaria de Educação Fundamental. Parâmetros Curriculares Nacionais: $1^{\circ}$ e $2^{\circ}$ ciclos do ensino fundamental. Brasília: MEC, 1998.

BRASIL. Ministério da Educação. Secretaria da Educação Básica. Fundamentos pedagógicos e estrutura geral da BNCC. Brasília, DF, 2017. Disponível em: http://portal.mec.gov.br/index.php?option=com_docman\&view=download\&alias=56621bnccapresentacao-fundamentos-pedagogicos-estrutura-pdf\&category_slug=janeiro-2017-pdf\&Itemid=30192. Acesso em: 10 jan. 2017.

DAHLET, P. Dialogização enunciativa e paisagens do sujeito. In: BRAIT, B. (org). Bakhtin, dialogismo e construção do sentido. 2 ed. Campinas, SP: Editora da UNICAMP, 2005.

FARACO, C. A. Autor e autoria. In: BRAIT, Beth. (org.). Bakhtin: conceitos-chave. 4. ed. São Paulo: Contexto, 2007. p. 37-60.

FRANCHI, C. Criatividade e gramática. Trabalhos em Linguística Aplicada, v. 9, p. 5-45, 1987. Disponível em: http://revistas.iel.unicamp.br/index.php/tla/article/view/3748. Acesso em: 15 jun. 2015.

GASPAROTTO, D.; MENEGASSI, J. R. A mediação do professor na revisão e reescrita de textos de aluno de Ensino Médio. Revista Calidoscópio, São Leopoldo, RS, v. 11, n.1, p. 2943, jan./abr., $2013 . \quad$ Disponível em: http://revistas.unisinos.br/index.php/calidoscopio/article/viewFile/cld.2013.111.04/1421. Acesso em: 13 set. 2016.

GERALDI, J. W. (org). O texto na sala de aula. 4. ed. São Paulo: Ática, 2006 [1984].

GERALDI, J. W. Portos de passagem. 5. ed. São Paulo: Martins Fontes, 2013 [1991].

PARANÁ. Secretaria de Estado da Educação. Diretrizes Curriculares da Educação Básica: Língua Portuguesa. Curitiba: SEED, 2008. 
POLATO, A. D. M. Análise Linguística: do estado da arte ao estatuto dialógico. 2017. 231f. Tese (Doutorado em Letras) -

Universidade Estadual de Maringá, Maringá, 2017. Disponível em: http://www.ple.uem.br/defesas/def_adriana_delmira_mendes_polato_do.html. Acesso em: 04 jan. 2018.

POLATO, A. D. M.; MENEGASSI, R. J. O estilo verbal como o lugar dialógico e pluridiscursivo das relações sociais: um estatuto dialógico para a análise linguística. Bakhtiniana - Revista de Estudos do Discurso, São Paulo, v. 12, p. 123-143, 2017. Disponível em: https://revistas.pucsp.br/index.php/bakhtiniana/article/view/27809/22670. Acesso em: 19 set. 2017.

RUIZ, E. D. Como corrigir redações na escola: uma proposta textual-interativa. 1. reimp. São Paulo: Contexto, 2010.

SOBRAL, A. U.; GIACOMELLI, K. Memória, imprecisões, sentidos: em torno da proposta bakhtiniana de estudos da linguagem. Revista Linguagem \& Ensino, Pelotas, RS, v. 21, n. esp., |VIII SENALE| p. 395-432, 2018. Disponível em: http://www.rle.ucpel.tche.br/index.php/rle/article/view/1971/1217. Acesso em: 25 jul. 2018.

VOLOCHINOV, V. N./ BAKHTIN, M. Discurso na vida e discurso na arte (sobre poética sociológica). Tradução Carlos Alberto Faraco e Cristóvão Tezza [para fins didáticos]. 1926. Versão da língua inglesa de I. R. Titunik a partir do original russo.

\section{(๑) $\circledast \odot$}

Recebido em 02/10/2018. Aceito em 29/10/2018. 